\title{
CARACTERÍSTICAS POLÍTICAS E DESEMPENHO FINANCEIRO PÚBLICO SOB A LUZ DA TEORIA DOS CICLOS POLÍTICOS
}

\author{
POLITICAL CHARACTERISTICS AND PUBLIC FINANCIAL \\ PERFORMANCE UNDER THE LIGHT OF THE POLITICAL \\ CYCLES THEORY
}

\section{CARACTERÍSTICAS POLÍTICAS Y DESEMPEÑO FINANCIERO PÚBLICO BAJO LA LUZ DE LA TEORÍA DE LOS CICLOS POLÍTICOS}

\section{Clóvis Fiirst}

Mestre em Ciências Contábeis pela Universidade Regional de Blumenau (FURB) - Brasil Professor do Departamento de Contabilidade Unioeste - Cascavel - PR - Brasil

cfiirst@gmail.com

\author{
Alexandre Corrêa dos Santos \\ Mestre em Ciências Contábeis pela Universidade \\ Regional de Blumenau (FURB) - Brasil \\ Perito Contador - Ibiporã - PR - Brasil \\ acs@atuaris.com.br \\ Moacir Manoel Rodrigues Junior \\ Doutor em Métodos Numéricos em Engenharia \\ da Universidade Federal do Paraná (UFPR) - \\ Brasil \\ Professor Permanente do Programa de Pós- \\ Graduação em Ciências Contábeis da \\ Universidade Regional de Blumenau \\ (PPGCC/FURB)/ SC - Brasil \\ moacir_ro@hotmail.com

\section{Vinícius Costa da Silva Zonatto} \\ Pós-doutor em Ciências Contábeis \\ (UNISINOS)/Brasil \\ Doutor em Ciências Contábeis e Administração \\ (FURB)/Brasil \\ Professor Adjunto do Departamento de Ciências \\ Contábeis da Universidade Federal de Santa \\ Maria (DCC/UFSM)/Brasil \\ viniciuszonatto@gmail.com
}

\author{
Contextus \\ ISSNe 2178-9258 \\ Organização: Comitê Científico Interinstitucional \\ Editor-Chefe: Diego de Queiroz Machado \\ Avaliação: double blind review pelo SEER/OJS \\ Recebido em 07/09/2018 \\ Aceito em 16/10/2018 \\ $2^{\text {a }}$ versão aceita em $25 / 10 / 2018$ \\ http://dx.doi.org/10.19094/contextus.v17i1.33608
}

\begin{abstract}
RESUMO
Um dos principais sinalizadores da eficácia de políticas públicas é a execução orçamentária, que deve refletir os interesses sociais nos aspectos qualitativo e quantitativo, bem como concretizar-se nas aplicações de recursos de forma transparente e sustentável. No entanto, estudos mostram que o desempenho financeiro público é afetado pelos ciclos políticos, o que indica retrocesso político e democrático. Este estudo descritivo, documental e quantitativo objetiva verificar a influência de características políticas no desempenho financeiro dos municípios paranaenses, sob a lente da teoria dos ciclos políticos. Os dados do período de 2013 a 2016, de 377 municípios, foram coletados junto aos sites do TCE-PR, TSE e IBGE e foram analisados por regressão múltipla com dados em
\end{abstract}


painel. Os resultados revelam que o ano eleitoral influencia positivamente o desempenho financeiro, porém tal relação é negativa em períodos em que ocorre mudança de gestor.

Palavras-Chave: características políticas; desempenho financeiro; ano eleitoral; execução orçamentária; ciclos políticos.

\begin{abstract}
One of the main indicators of the effectiveness of public policies is budget execution, which should reflect social interests in the qualitative and quantitative aspects and be implemented in harnessing resources in a transparent and sustainable way. However, studies show that public financial performance is affected by political cycles, which indicates political and democratic backwardness. This descriptive, documental and quantitative study aims to verify the influence of political characteristics on the financial performance of the municipalities of Paraná, under the lens of the theory of political cycles. Data, from the period 2013 to 2016, of 377 municipalities were collected from the TCE-PR, TSE and IBGE sites and were analyzed by multiple regression with panel data. The results show that the electoral year positively influences the financial performance, however this relationship is negative in periods when government is changed.
\end{abstract}

Keywords: political characteristics; financial performance; election year; budget execution; political cycles.

\title{
RESUMEN
}

Uno de los principales indicadores de la eficacia de políticas públicas es la ejecución presupuestaria, que debe reflejar los intereses sociales en los aspectos cualitativo y cuantitativo, se concretando en las aplicaciones de recursos de forma transparente y sostenible. Sin embargo, estudios muestran que el desempeño financiero público es afectado por los ciclos políticos, lo que indica retroceso político y democrático. Este estudio descriptivo, documental y cuantitativo objetiva verificar la influencia de características políticas en el desempeño financiero de los municipios paranaenses, bajo la lente de la teoría de los ciclos políticos. Los datos del período de 2013 a 2016, de 377 municipios, fueron recolectados junto a los sitios del TCE-PR, TSE y IBGE y analizados por regresión múltiple con datos en panel. Los resultados revelan que el año electoral influye positivamente en el desempeño financiero, pero tal relación es negativa en períodos en que ocurre cambio de gestor.

Palabras-clave: características políticas; desempeño financiero; año electoral; ejecución presupuestaria; ciclos políticos.

\section{INTRODUÇÃO}

Diante das recentes crises econômicas dos últimos anos, a nova gestão pública brasileira, sob a égide da Lei de Responsabilidade Fiscal (LRF, 2018), tem pautado, em valores democráticos pleiteados pela sociedade civil, esforços para cumprir agendas financeiras que mais se aproximam de mecanismos de mercado (RODRIGUES, 2017). Embora isso não seja necessariamente incorreto, a sonhada transparência pública trouxe à vista um cenário de endividamento e dificuldades financeiras dos entes públicos, que pode conflitar com os interesses coletivos de investimentos sociais a curto prazo.

Tais problemas são tratados pela teoria dos ciclos políticos. Geralmente, a proximidade de eleições afeta as escolhas políticas (MARTINEZ, 2009), sendo comum nesse período os políticos induzirem melhores condições econômicas, pois os votos populares em geral decorrem de sua performance. Essa teoria oriunda de Nordhaus (1975) implica que os gestores são dirigidos por interesses privados e ocupam-se prioritariamente de suas perspectivas de reeleição, exploram a curva de Phillips de curto prazo e beneficiam-se das expectativas 
medianas dos eleitores para atingir seus objetivos (VICENTE; NASCIMENTO, 2012; DUBOIS, 2016).

Os pressupostos da teoria de Nordhaus (1975) abrangem variáveis de desempenho como a taxa de desemprego e a de inflação, antes e após o período eleitoral. No entanto, pesquisas recentes têm discutido esses fundamentos, considerando que tais variáveis não são de controle do poder público e, portanto, oferecem pouca explicação teórica para o comportamento oportunista do gestor público.

Nesse contexto, Ales, Maziero e Yaref (2014) enfatizam que os políticos detêm informações privadas sobre restrições orçamentárias e ações para captar rendas públicas, que podem ser utilizadas em forma de ações mais benevolentes ao eleitor. Tal fato pode ser verificado em novas democracias, pois tais manipulações são encontradas de forma mais ampla devido à falta de experiência com políticas eleitorais e informações disponíveis (BRENDER; DRAZEN, 2005).

No caso do Brasil, pesquisas (QUEIROZ; SILVA, 2010; COVRE; MATTOS, 2016; GONÇALVES; FUNCHAL; FILHO, 2017; LEITE; GUSE; HEIN, 2017; QUEIROZ, 2017) apontam um embasamento empírico de que o ciclo político é um fenômeno recorrente (SIQUEIRA, 2016). Entretanto, para Nakaguma e Bender (2010), há evidências de redução na amplitude dos ciclos políticos ao longo do tempo, o que poderia ser atribuído à aprendizagem do eleitorado e à experiência adquirida com eleições sucessivas, que contribuem para elevar o nível de controle político e reduzir a intensidade dos ciclos.

Diante disso, Philips (2017) aponta que há uma vasta literatura sobre ciclos políticos no Leste Europeu e Estados Unidos, porém com várias teorias e resultados empíricos conflitantes entre si. Há uma tendência de mudança recente dessa literatura para países em desenvolvimento, como o Brasil.

Tais apontamentos revelam lacunas na literatura a serem exploradas sob a ótica de mudança de gestor público, gestor de primeiro mandato e ano eleitoral. Estes são pressupostos da teoria dos ciclos políticos, capazes de afetar o desempenho financeiro. Tais implicações temporais são relevantes, e o estudo recente de Sidorkin e Vorobyev (2018) encontrou na Rússia uma associação positiva entre ciclos políticos e corrupção. Notadamente, quando o gestor público obtém informações de que não será reeleito, pode ter propensão para envolver-se em atividades corruptas com o fim de acumular riqueza. 
Nesse sentido, o sistema político brasileiro é complexo e muitas decisões tomadas refletem interesses oportunistas dos gestores públicos que se sobrepõem aos desejos da sociedade. Uma das maneiras para captar tais comportamentos oportuníssimos é observar o desempenho financeiro.

Diante do exposto, elaborou-se a seguinte questão de pesquisa: qual a influência de características políticas no desempenho financeiro dos municípios paranaenses, sob a ótica da teoria dos ciclos políticos? Esta pesquisa objetiva verificar a influência de características políticas no desempenho financeiro dos municípios paranaenses, sob a ótica da teoria dos ciclos políticos.

O avanço neste conhecimento pode melhorar a compreensão dos efeitos dos ciclos políticos sobre o desempenho financeiro, fornecendo dados capazes de ser utilizados para melhorar a observação social em relação à eficácia da gestão pública ao longo do mandato. $\mathrm{O}$ estudo pretende investigar uma amostra de 399 municípios do Estado do Paraná, a fim de proporcionar a expansão da pesquisa e conhecimento em relação à gestão e desempenho no setor público. Dessa forma, busca contribuir com o interesse social, por meio de evidências sobre as características políticas e ainda ampliar a discussão da teoria dos ciclos políticos em municípios e sua relação com o desempenho financeiro.

Na sequência, o trabalho é apresentado em quatro seções que se iniciam pela descrição dos antecedentes e busca fundamentar as hipóteses deste estudo, em seguida adentra na explicação dos procedimentos metodológicos e analisa e discute os resultados obtidos. Posteriormente aborda as considerações finais e limitações do estudo.

\section{ANTECEDENTES E FUNDAMENTAÇÃO DAS HIPÓTESES}

Nesta seção, busca-se apresentar os pressupostos da teoria dos ciclos políticos e os pontos críticos ligados à sua relação com o orçamento público e a relação das características políticas com o desempenho financeiro obtido pelos municípios. Portanto, busca-se apresentar os principais estudos que fundamentam as hipóteses deste trabalho.

Analisar a teoria dos ciclos políticas sob a perspectiva de Nordhaus (1975), que sugere o conhecimento mediano dos eleitores nos dias atuais, pode representar uma posição um tanto limitada e conservadora frente às exigências da nova gestão pública, dos mecanismos de 
governança pública e dos interesses da sociedade civil globalizada, que a cada dia aumenta o controle social por meio de observatórios, participação popular, mídia e outros mecanismos.

Todavia, estudos internacionais na Alemanha (GARMANN, 2017), na Itália (ALESINA; PARADISI, 2017) e em um conjunto de países (CASTRO; MARTINS, 2017), evidenciam a presença de oportunismo durante o ciclo político, seja por meio do aumento de incentivos tributários em anos de eleição ou pelo direcionamento de gastos em serviços públicos como educação e saúde, portanto, denota a ocorrência de disfunções nos ciclos políticos.

No Brasil, estudos como o de Zucolotto e Teixeira (2017) sinalizam que caminhamos a passos lentos em relação à mitigação de práticas eleitoreiras, haja vista não termos atingido sequer um nível de transparência orçamentária que atenda à essência da LRF. No estudo, dentre as causas observadas para a baixa transparência, encontrou-se o fator vontade política.

Em decorrência disso, observou-se nos últimos anos no Brasil que os ciclos políticos continuam apresentando efeito de exploração sobre a sociedade. O estudo de Correia e Neduziak, (2017) mostrou que o comportamento da variável gastos e despesas com pessoal tem sido perverso em relação à variação de bem-estar dos Estados e Distrito Federal: verifica-se, em média, para uma variação de um ponto percentual dessa variável, um decrescimento do PIB na ordem de 2 pontos percentuais.

No Estado de Santa Catarina, o estudo de Lautenschlage (2018) investigou 292 municípios catarinenses entre 2003 e 2014 e encontrou que, no ano subsequente às eleições municipais, há uma redução nas despesas totais, nos investimentos e nos tributos arrecadados, com uma melhora no saldo fiscal. Nesta mesma linha de estudos, Nunes (2017) investigou a ocorrência de ciclos políticos no Estado do Rio Grande do Sul entre 2002 e 2012, encontrando evidências de recomposição de dívidas.

Em um estudo com maior amplitude geográfica, Gomes, Bastos e Almeida (2018) investigaram evidências de ciclos políticos e eleitorais nas despesas com a função saúde e saneamento nos municípios brasileiros entre 1998 e 2012 e a influência da origem de recursos e diferenças partidárias sobre a alocação destas despesas. O resultado deste estudo com dados em painel também propiciou observar a dinâmica da formação de possíveis ciclos eleitorais, ou seja, o aumento das despesas com saúde e saneamento nos anos anteriores e no próprio ano da eleição municipal.

Mediante os estudos analisados, é possível verificar que a manipulação intencional do ciclo político geralmente ocorre em paralelo à alteração da política fiscal, operacionalizada por 
meio do artefato gerencial do orçamento público (AASKOVEN; LASSEN, 2017). Portanto, podem ocorrer, simultaneamente, o ciclo político e o ciclo orçamentário.

Decorrente disso, alguns países, estados ou municípios com um ciclo orçamentário político podem incentivar políticas fiscais que favoreçam políticos no governo, detentores da máquina pública (KLOMP; HAAN, 2013). Este tipo de comportamento se confirmou no estudo de Klein e Sakurai (2015), que verificaram a ação de prefeitos os quais, mediante oportunidade de maximizar sua chance de reeleição, alteraram a composição do orçamento em anos eleitorais, conforme preveem os modelos de sinalização dos ciclos políticos orçamentários.

Contudo, uma recente abordagem teórica investiga uma nova visão científica, em que o fator transparência emerge como responsável pela diminuição dos ciclos orçamentários. Nesta direção, Herzog (2017) estudou um conjunto de 99 países em desenvolvimento e outros 34 da organização para Cooperação Econômica e Desenvolvimento de Países, cujo resultado confirmou, por meio de dados econométricos de 1970 a 2014, que países com maior transparência apresentam ciclos menores, com destaque aos países do G8.

No entanto, contrário a essa nova tendência, o pressuposto da teoria dos ciclos políticos levanta a hipótese de que gestores públicos tendem a maximizar resultados, quer sejam no campo financeiro, econômico, orçamentário ou social, em períodos eleitorais. Este fenômeno ainda é mais intenso quando os políticos exercem o primeiro mandato. Tal comportamento busca garantir uma melhor visibilidade entre os stakeholders (sociedade, tribunais de contas, ministério público, observatório sociais, poderes fiscalizadores), pois são institutos que exercem o controle social no Estado de direito.

Diversos estudos (VEIGA; F.J. VEIGA, 2001; SAKURAI, 2005; SHI; SVENSON, 2006; SALVATO; ANTUNES; ARAUJO Jo; SHIKIDA, 2007; CARVALHO; OLIVEIRA, 2009; EBEKE; ÖLÇER, 2013; ANESSI-PESSINA et al., 2012; MARTINS; CORREIA, 2015) têm concentrado esforços em investigações a respeito de características políticas como ano eleitoral, mudança de gestor e gestor de primeiro mandato.

No rol desta natureza de estudos, Queiroz (2017) chama a atenção para essas relações, ao analisar o desempenho do gestor, nesse caso medido pelos gastos públicos ano a ano durante ciclos políticos das unidades federativas, demonstrando um efeito subsequente ao ano eleitoral. Esses achados geram oportunidades de pesquisas ao analisar o comportamento político do gestor com outros indicadores de desempenho, como exemplo o proposto para esse estudo (performance finance) com aplicação em municípios. 
Adotado como proxy, o desempenho financeiro no setor público é observado nos estudos internacionais, como por exemplo Robbins e Turley e McNena (2016), que contribuíram com os conselhos locais na Irlanda, ao desenvolver métricas voltadas ao desempenho financeiro, utilizando a base da literatura já aplicada nos governos locais dos EUA e as diretrizes internacionais da OCDE.

Por sua vez, Torres, Pina e Marti (2012) analisaram medidas de desempenho não obrigatórias nos governos locais da Espanha. Para tanto, utilizaram indicadores financeiros para fazer as comparabilidades e triangulações dos dados.

Mais um estudo relevante foi proposto por Tantardini; Guo e Ganapati (2017), que relacionaram desempenho financeiro com capital humano no estado da Flórida (EUA) e cujos resultados reforçam a influência positiva dos investimentos em estrutura de capital intelectual sobre indicadores financeiros do setor público.

Considerando que os estudos anteriores brasileiros não abordam especificamente a relação entre o desempenho financeiro e as características políticas, vislumbra-se uma oportunidade de pesquisa, pois essa variável é utilizada na literatura internacional aplicada ao setor público. Neste contexto, com base nos pressupostos da teoria dos ciclos políticos e nos estudos correlatos apresentados, esperam-se as seguintes relações descritas nas hipóteses a seguir:

$\boldsymbol{H}_{1}$ : Existe influência positiva do ano eleitoral no desempenho financeiro em municípios paranaenses.

$\boldsymbol{H}_{2}$ : Existe influência positiva, quando o gestor é de primeiro mandato, no desempenho financeiro em municípios paranaenses.

$\boldsymbol{H}_{3}$ : Existe influência negativa, quando da mudança de gestor público, no desempenho financeiro em municípios paranaenses.

Se os resultados empíricos comprovarem as hipóteses levantadas, este estudo possibilitará melhor compreensão do ciclo político investigado, permitindo aos cidadãos olhar o cenário político por outra perspectiva, que vai além das preferências eleitorais pessoais e analisa os resultados efetivos de um gestor público durante o período em que exerceu o mandato.

Portanto, compreender o ciclo político sob o ponto de vista do desempenho do gestor, abre oportunidades para despertar o senso crítico nos cidadãos e estimula o exercício da 
democracia participativa e do controle social, uma importante variável que contribui para evitar comportamentos oportunistas dos gestores públicos.

\section{PROCEDIMENTOS METODOLÓGICOS}

\subsection{Delineamento da pesquisa, amostra e coleta de dados}

O delineamento da pesquisa é descritivo por observar variáveis sem manipulá-las, documental por utilizar dados secundários publicado em portais eletrônicos públicos, e a abordagem do problema é quantitativa por verificar a influência do ano eleitoral, mudança de gestor público e mandato eleitoral no desempenho financeiro, por meio de regressão linear múltipla.

A população da pesquisa compreende 399 municípios paranaenses, no entanto a amostra final apresenta-se com 377 municípios, devido ao fato de que 22 deles não apresentaram dados suficientes para o estudo.

Os dados foram coletados no mês de julho de 2018 e correspondem ao ciclo eleitoral do período do ano de 2013 a 2016, em que os dados financeiros/contábeis foram coletados no site do Tribunal de Contas do Estado do Paraná (TCE-PR) e foram auditados pelo respectivo órgão de controle externo.

As características eleitorais foram capturadas no portal eletrônico do Tribunal Superior Eleitoral (TSE) e os dados da população por município foram obtidos do último censo disponibilizado no site do Instituto Brasileiro de Geografia e Estatística (IBGE).

\subsection{Variáveis e Modelo Econométrico}

Com o objetivo de responder à questão de pesquisa ora proposta, elaborou-se a Tabela 1, como forma de detalhar as variáveis dependentes e explicativas a serem analisadas, assim como também aponta o resultado esperado das relações entre as variáveis propostas na modelagem e apresenta o detalhamento da equação matemática que representa cada variável adotada no presente estudo. 
Tabela 1 - Variáveis adotadas na pesquisa

\begin{tabular}{|c|c|c|c|c|}
\hline Variáveis & Indicador & Fórmula & $\begin{array}{c}\text { Relação } \\
\text { esperada }\end{array}$ & $\begin{array}{c}\text { Leis/Autores que } \\
\text { utilizaram a } \\
\text { variável }\end{array}$ \\
\hline Dependente & $\begin{array}{c}\text { DF } \\
\text { (Desempenho } \\
\text { Financeiro) }\end{array}$ & $\begin{array}{l}\text { Evidencia a diferença positiva entre o } \\
\text { ativo e o passivo financeiros, bem como } \\
\text { considera os saldos de créditos adicionais } \\
\text { transferidos e as operações de créditos a } \\
\text { eles vinculadas. } \\
\text { DF = AF - PF, } \\
\text { em que: } \\
\text { AF = Ativo Financeiro } \\
\text { e } \\
\text { PF = Passivo Financeiro }\end{array}$ & & (Brasil, 1964) \\
\hline \multirow{4}{*}{ Explicativas } & $\begin{array}{c}\mathbf{A E} \\
\text { (Ano Eleitoral) }\end{array}$ & $\begin{array}{l}\text { Variável categórica: valor } 1 \text { em ano de } \\
\text { eleicão e zero em caso contrário }\end{array}$ & + & \multirow{4}{*}{ (Queiroz, 2017) } \\
\hline & $\begin{array}{c}\text { MGP } \\
\text { (Mudança de } \\
\text { Gestor Público) }\end{array}$ & $\begin{array}{l}\text { Variável categórica: valor } 1 \text { se o prefeito } \\
\text { do município é diferente do ano anterior } \\
\text { e zero em caso contrário }\end{array}$ & - & \\
\hline & $\begin{array}{l}\text { PME } \\
\text { (Primeiro } \\
\text { Mandato } \\
\text { Eleitoral) }\end{array}$ & $\begin{array}{l}\text { Variável categórica: valor } 1 \text { se o prefeito } \\
\text { do município exerce o primeiro mandato } \\
\text { eleitoral e zero para o contrário }\end{array}$ & + & \\
\hline & $\begin{array}{c}\text { POP } \\
\text { (População) }\end{array}$ & Logaritmo natural da população & + & \\
\hline
\end{tabular}

Fonte: elaboração própria.

O modelo econométrico adotado neste estudo, para testar a influência de características políticas sobre o desempenho financeiro dos municípios paranaenses, é apresentado alinhando as hipóteses levantas $H_{1}, H_{2}, H_{3}$ e encontra-se descrito na Equação 1:

$D F_{i t}=\beta_{i}+\beta_{1} A E_{i t}+\beta_{2} M G P_{i t}+\beta_{3} P M E_{i t}+\beta_{4} P O P_{i t}+e_{i t \ldots .} 01$

Para analisar os dados desta pesquisa, foram empregadas técnicas estatísticas de regressão linear múltipla com dados em painel, com auxílio do software estatístico Stata® versão 14, buscando averiguar pressupostos fundamentais como a significância do modelo, autocorreção, multicolinearidade, homocedasticidade e o poder explicativo do modelo.

A identificação da modelagem em painel a ser utilizada, se efeitos fixos, efeitos aleatórios ou Pols, remete ao teste de Breusch-Pagan no critério estatístico em nível de 5\% (maior que 0,05 Chow e, menor que 0,05 Hausman). O teste Chow é observado pelo julgamento, maior que 0,05 utiliza-se regress e menor que 0,05 utiliza-se o efeito fixo. 
Finalmente o resultado do teste de Hausman, direciona que, se o resultado for maior que 0,05 utiliza-se efeitos aleatórios e, caso for menor que 0,05 utiliza-se o efeito fixo (GREENE, 2008).

\section{ANÁLISE E DISCUSSÃO DOS RESULTADOS}

A análise dos resultados foi organizada de forma a responder à questão de pesquisa, atender ao objetivo e às hipóteses levantadas. Para tanto, elaborou-se a Tabela 2, com o propósito de evidenciar o resultado da regressão prevista na Equação 1.

Tabela 2 - Resultados da regressão Equação 1

\begin{tabular}{|c|c|c|c|c|c|c|c|}
\hline Prob $>$ F & $\mathbf{R}^{2}$ & DW & $\begin{array}{c}\text { Teste } \\
\text { White }\end{array}$ & $\begin{array}{l}\text { Teste } \\
\text { B e P }\end{array}$ & F de Chow & $\begin{array}{c}\text { Teste } \\
\text { Hausman }\end{array}$ & $\mathbf{N}^{\circ} \mathrm{OBS}$ \\
\hline 0.0000 & 0.14 & 1.68 & 0.0616 & 0.0000 & 0.0000 & 1.0000 & 1.508 \\
\hline \multirow{2}{*}{ Var. Indep. } & \multicolumn{7}{|c|}{ Efeitos aleatórios } \\
\hline & Coeficiente & Erro padrão & $T$ & P-Value & VIF & \multicolumn{2}{|c|}{ Interv. Conf. 95\% } \\
\hline $\mathrm{AE}$ & .2308844 & .1131649 & 2.04 & $0.041 * *$ & 1.18 & .0090853 & .4526836 \\
\hline PME & -.0778264 & .2495082 & -0.31 & 0.755 & 1.09 & -.5668534 & .4112006 \\
\hline MGP & -.4013065 & .129927 & -3.09 & $0.002 * * *$ & 1.09 & -.6559588 & -.1466543 \\
\hline POP & .795368 & .1027426 & 7.74 & $0.000 * * *$ & 1.00 & .5939961 & .9967399 \\
\hline Cons & 6.183217 & .9821532 & 6.30 & 0.000 & ------------------- & 4.258232 & 8.108202 \\
\hline
\end{tabular}

Legenda: Prob>F: significância do Modelo; R2: poder explicativo do modelo; DW: Durbin-Watson autocorrelação; Teste White: teste de heterocedasticidade dos resíduos; Teste B e P: Breusch and Pagan verificação da adequação da modelagem em painel; $F$ de Chow: verificação da adequação da modelagem em painel; Teste Hausman: verificação da adequação da modelagem em painel.

***Significância ao nível de até 1 ; ** Significância ao nível de até 5; *Significância ao nível de até 10 Fonte: elaboração própria.

Os resultados dos testes de Breusch-Pagan, F de Chow e de Hausman, apresentados na Tabela 2 e relativos à Equação 1, demonstram que a modelagem apropriada para analisar a amostra estudada com dados em painel é a de efeitos aleatórios, tendo em vista que o teste de Breusch-Pagan se apresentou menor que 0,05. Em consequência, direcionou-se a verificação do teste de Hausman, maior que 0,05 , condicionando portanto a modelagem de efeitos aleatórios.

A modelagem estatística utilizada neste estudo é significante ao nível de $1 \%$ com 1.508 observações, correspondendo à amostra de 377 municípios com dados do ciclo político de 2013 a 2016. O poder explicativo do modelo $\left(\mathrm{R}^{2}\right)$ é de $14 \%$ e não apresentou problemas de autocorrelação, tendo em vista que o valor do Durbin-Watson é 1.68 (HILL; JUDGE; GRIFFITHS, 2010). Os valores do VIF não demonstram o efeito da multicolinearidade nas 
variáveis do estudo (VIF>5). O teste de White (0.0616) não indica dispersão dos resíduos (problema de heterocedasticidade), demonstrando que os dados são homoscedásticos.

Conforme apontam os resultados estatísticos (p-valor 5\% e influência positiva) relativos à variável ano eleitoral (AE), o desempenho financeiro em período eleitoral é maior, o que ratifica o pressuposto da teoria dos ciclos políticos. Essa evidência confirma o comportamento oportunista do gestor em períodos eleitorais ao mostrar em termos financeiros uma boa visibilidade das contas públicas (NORDHAUS, 1975; DOWNS, 1957).

A variável mudança de gestor público (MGP) apresenta nível de significância de 1\% com relação negativa. No período de transmissão de mandato eleitoral, o gestor que deixa o ciclo político tende a não fazer maiores esforços para melhorar o equilíbrio financeiro das contas públicas.

Os resultados estatísticos correspondentes à variável gestor de primeiro mandato (PME) não foram significativos para demonstrar as relações esperadas. A variável de controle de população (POP) foi significante ao nível de $1 \%$, o que indica a variação de maior intensidade do superávit financeiro, portanto, essa associação segue a lógica da arrecadação da receita per capita por município.

Diante disso, os resultados revelam uma influência positiva do ano eleitoral no desempenho financeiro em municípios paranaenses, ou seja, em períodos eleitorais os gestores tendem a demonstrar um resultado positivo da execução financeira (diferença entre o ativo e passivo financeiro) das contas públicas. Esses achados corroboram o pressuposto teórico dos ciclos políticos (NORDHAUS, 1975), o que sugere comportamentos oportunistas dos gestores em épocas eleitorais, pois buscam mostrar estabilidade diante dos stakeholders envolvidos no controle social. Além disso, esses resultados ratificam os testes empíricos da literatura sobre o tema ciclos políticos, como por exemplo o estudo (ANESSI-PESSINA; SICILIA; STECCOLINI, 2012) nos governos locais italianos.

Outra implicação que merece ser discutida e aprofundada sobre superávit financeiro em ano eleitoral refere-se ao fato de esse indicador ser uma das fontes previstas na legislação de finanças públicas brasileira (Lei 4.320/1964), para cobertura de créditos adicionais orçamentários. Em outras palavras, saldos positivos podem ser utilizados para remanejamento de recursos dentro dos orçamentos vigentes, pois compreendem uma fonte de recurso para sustentar modificações no planejamento financeiro e orçamentário dos governos. 
Portanto, a necessidade de dinamizar o orçamento em período eleitoral por parte dos gestores públicos pode explicar a relação encontrada neste estudo (influência positiva do ano eleitoral sobre o desempenho - SUP), o que leva a aceitar a hipótese $H_{l}$ nesse estudo e avançar nas discussões dos ciclos políticos utilizando a proxy desempenho financeiro, discutida em estudos internacionais (TORRES; PINA; MARTI, 2012; ROBBINS; TURLEY; McNENA, 2016; TANTARDINI; GUO; GANAPATI, 2017) que encontraram diversas relações nas gestões públicas municipais.

Além disso, em anos em que ocorre a mudança de gestor, os resultados mostram uma influência negativa ao nível de significância de $1 \%$, ou seja, o desempenho financeiro nos períodos de transições é menor. Uma possível explicação consiste na finalização de um ciclo eleitoral, em que gestores não tendem a maximizar os resultados como em períodos eleitoreiros, em razão de que estão deixando o seu mandato e não estão necessariamente interessados em manter uma boa visibilidade. Essa discussão é alinhada ao pressuposto da teoria dos ciclos político (DOWNS, 1957) e permite aceitar a hipótese $H_{3}$ dessa pesquisa.

Outros estudos, como Queiroz (2017), também relacionou a variável mudança de gestor, no entanto utilizou a proxy composição de gasto público, e os resultados foram diferentes dessa pesquisa, pois o autor encontrou relação positiva entre mudança de gestor e composição do gasto público, mas em análise paralela entre as variáveis desempenho financeiro e composição do gasto. Contudo, por analogia, é possível verificar uma convergência entre os resultados.

Essas implicações condicionam dar continuidade na discussão das características políticas com outros eventos financeiros e orçamentários do setor público e corroboram a literatura relacionada (VEIGA; F. J. VEIGA, 2001; SAKURAI, 2005; SHI; SVENSON, 2006; SALVATO; ANTUNES; ARAUJO J'.; SHIKIDA, 2007; CARVALHO; OLIVEIRA, 2009; EBEKE; ÖLÇCER, 2013; ANESSI-PESINA et al., 2012; MARTINS; CORREIA, 2015).

Os resultados da regressão para a hipótese $H_{2}$ não foram significantes ao nível de aceitabilidade estatística desse estudo (1\%,5\% e 10\%), portanto, não é possível verificar as relações esperadas. No entanto, uma observação interessante que se levanta para discussão é o comportamento do coeficiente para variável (PME) de períodos em que os gestores são de primeiro mandato, em que o sinal foi negativo. Isso pode ser explicado pela incompatibilidade do lapso temporal entre a vigência do mandato eleitoral e o plano plurianual e ainda a expertise do gestor. Essas implicações são oportunidades para futuras investigações com uso de variáveis que consigam acompanhar a performance de gestores que tomaram posse pela primeira vez em administrações públicas e ainda ampliar o leque de discussões da teoria dos ciclos políticos. 


\section{CONSIDERAÇÕES FINAIS}

O objetivo deste estudo foi verificar a influência de características políticas no desempenho financeiro dos municípios paranaenses, sob a ótica da teoria dos ciclos políticos. Para tanto, utilizou-se uma amostra de 377 municípios paranaenses, com delineamento metodológico descritivo, documental e quantitativo. O período de análise correspondeu ao ciclo político de 2013 a 2016.

As evidências confirmam a existência de um comportamento oportunista dos gestores públicos na amostra em análise, tanto para o fator ano eleitoral, como em anos em que ocorre a mudança de gestor público nos municípios paranaenses, o que suporta as hipóteses $H_{1}$ (Existe influência positiva do ano eleitoral no desempenho financeiro nos municípios paranaenses) e $\mathrm{H}_{3}$ (Existe influência negativa quando da mudança de gestor público no desempenho financeiro nos municípios paranaenses), respectivamente.

Esses resultados estão alinhados e corroboram o pressuposto da teoria dos ciclos políticos (NORDHAUS, 1975; DOWNS, 1957) e outros estudos empíricos (VEIGA; F. J. VEIGA, 2001; SAKURAI, 2005; SHI; SVENSON, 2006; SALVATO; ANTUNES; ARAUJO JUNIOR; SHIKIDA, 2007; CARVALHO; OLIVEIRA, 2009; EBEKE; ÖLÇER, 2013; ANESSI-PESSINA et. al., 2012; MARTINS; COCRREIA, 2015).

Ademais, os resultados demonstram que o ano eleitoral influencia positivamente o desempenho financeiro. Sob a visão teórica dos ciclos políticos, existe um comportamento oportunista do gestor público, ou seja, a manutenção de uma boa visibilidade nesse período em termos de contas públicas é oportuna junto aos envolvidos no processo de controle social e fiscalização externa. Outra implicação para esse resultado superavitário é a oportunidade de o gestor usar essa sobra como uma das fontes de recursos para cobrir aberturas de créditos adicionais - são remanejamentos do orçamento previamente planejado e aprovado.

Todavia, em períodos com mudança de gestor, os achados revelam uma influência negativa com nível de significância de $1 \%$. Isso decorre do fato de, em épocas de transição de gestores da administração pública municipal, os saldos positivos das sobras financeiras tenderem a diminuir, dado que é o momento de finalização de mandatos eletivos. Isso também corrobora as premissas da teoria dos ciclos políticos (DOWNS, 1957).

Em complementação aos achados relacionados com a $H_{1}$ e $H_{3}$, apesar de os resultados estatísticos não serem significativos para $\mathrm{H}_{2}$ (Existe influência positiva quando o gestor é de 
primeiro mandato no desempenho financeiro nos municípios paranaenses), nota-se que o comportamento do coeficiente para a variável PME é negativo, revelando oportunidades de futuras pesquisas com a referida variável que verifiquem outras relações, como por exemplo a expertise dos gestores iniciantes e sua performance financeira.

As limitações relacionam-se à amostra limitada de municípios, correspondentes a um Estado, uma vez que os dados disponíveis de municípios de outras unidades federativas são distintos e podem apresentar características heterogêneas. Sugere-se para futuras pesquisas utilizar outras variáveis de desempenho, como a execução orçamentária corrente e alocações em gastos priorizados e essenciais.

\section{REFERÊNCIAS}

AASKOVEN, L.; LASSEN, D. D. Political budget cycles. Research Encyclopedia of Politics, Oxford University Press, 2017.

ALES, L.; MAZIERO, P.; YARED, P. A theory of political and economic cycles. Journal of Economic Theory, v. 153, n. 1, p. 224-251, 2014. doi: https://doi.org/10.1016/j.jet.2014.07.004

ALESINA, A.; PARADISI, M. Political budget cycles: evidence from Italian cities. Economics \& Politics, v. 29, n. 2, p. 157-177, 2017. doi: https://doi.org/10.1111/ecpo.1209

ANESSI-PESSINA, E.; SICILIA, M.; STECCOLINI, I. Budgeting and rebudgeting in local governments: siamese twins? Public Administration Review, v. 72, n. 6, p. 875-884, 2012. doi: https://doi.org/10.1111/j.1540-6210.2012.02590.x

BRASIL. Lei $n^{0}$ 4.320, de 17 de março de 1964. Estatui normas gerais de direito financeiro para elaboração e controle dos orçamentos e balanços da União, dos Estados, dos Municípios e do Distrito Federal. Diário Oficial da União. Disponível em: <www.planalto.gov.br/ccivil_03/leis/14320.htm>. Acesso em: 25/jul/2018.

BRENDER, A.; DRAZEN, A. Political budget cycles in new versus established democracies. Journal of Monetary Economics, v. 52, n. 7, p. 1271-1295, 2005 . doi: https://doi.org/10.1016/j.jmoneco.2005.04.004

CARVALHO, F. A. A.; OLIVEIRA, K. V. A contabilidade governamental e a teoria dos ciclos políticos: uma análise empírica fiscal e contábil sobre os municípios do Estado do Rio De 
Janeiro - 1998/2006. Revista de Educação e Pesquisa em Contabilidade, v. 3, n. 1, p. 46-64, 2009. doi: http://dx.doi.org/10.17524/repec.v3i1.40

CASTRO, V.; MARTINS, R. Politically driven cycles in fiscal policy: In depth analysis of the functional components of government expenditures. European Journal of Political Economy, In Press, 2017. doi: https://doi.org/10.1016/j.ejpoleco.2017.11.003

CORREIA, F. M.; NEDUZIAKI, L. C. R. Crescimento econômico e ciclo político orçamentário: uma análise para os estados brasileiros. Revista de Desenvolvimento Econômico, v. 1, n. 36, p. 60-77, 2017. Disponível em <http://www.revistas.unifacs.br/index.php/rde/article/view/4671/3154> Acesso em: $07 / \mathrm{set} / 2018$.

COVRE, J.; MATTOS, L. B. A situação fiscal e os ciclos políticos nos municípios brasileiros: uma análise a partir de dados em painel dinamico espacial. Anais... Encontro Nacional dos Centros de Pós-Gaduação em Economia, 58, ANPEC - Associação Nacional dos Centros de Pós-Graduação em Economia, Brasil. 1-19, 2016.

DOWNS, A. An economic theory of political action in a democracy. Journal of Political Economy, v. 65, n. 2, apr. 1957.

DUBOIS, E. Political business cycles 40 years after Nordhaus. Public Choice, v. 166, n. 1-2, p. 235-259, 2016. doi: https://doi.org/10.1007/s11127-016-0313-Z

EBEKE, C.; OLÇER, D. Fiscal policy over the election cycle in low-income countries (IMF Working Paper WP/13/153), Washington, DC: International Monetary Fund, 2013.

GARMANN, S. Electoral cycles in public administration decisions: evidence from German municipalities. Regional Studies, v. 51, n. 5, p. 712-723, 2017. doi: https://doi.org/10.1080/00343404.2015.1120282

GOMES, B. S. M; BASTOS, S. Q. A.; ALMEIDA, E. S. Ciclos eleitorais e partidários e interação espacial nas despesas em saúde e saneamento municipais (1998-2012). Anais... XLIV Encontro Nacional de Economia - ANPEC - Associação Nacional dos Centros de PósGraduação em Economia , 2018.

GONÇALVES, L. G.; FUNCHAL, B.; FILHO, J. E. B. A influência dos ciclos políticos nos investimentos públicos em infraestrutura: um estudo nos estados brasileiros no período de 2003 a 2014. Revista de Administração Pública, v. 51, n 4, p. 462-481, 2017. doi: http://dx.doi.org/10.1590/0034-7612156337 
GREENE, W. H. The econometric approach to efficiency analysis. In. Harold, O. F, Lovell, C.A. K., Schmidit, S. S. The measurement of productive efficiency and productivity growth, 2008.

HERZOG, B. Does transparency mitigate the political budget cycle? Journal of Economic Studies, v. 44, n. 5, p. 666-689, 2017. doi: https://doi.org/10.1108/JES-07-2016-0132

HILL, C.; JUDGE, G. G.; GRIFFITHS, W. E. Econometria. 3. ed. São Paulo: Saraiva, 2010.

KLEIN, F. A.; SAKURAI, S. N. Term limits and political budget cycles at the local level: evidence from a young democracy. European Journal of Political Economy, v. 37, p. 21-36, 2015. doi: https://doi.org/10.1016/j.ejpoleco.2014.10.008

KLOMP, J.; HAAN, J. Political budget cycles and election outcomes. Public Choice, v. 157, n. 1-2, p 245-267, 2013. doi: https://doi.org/10.1007/s11127-012-9943-y

LAUTENSCHLAGE, J. Ciclos político-orçamentários nos municípios de Santa Catarina. Textos de Economia, v. 21, n. 1, p. 1-24, 2018. doi: https://doi.org/10.5007/21758085.2018v21n1p1

LEITE, M.; GUSE, J. C.; HEIN, N. Financial leverage and financial performance: Analysis on the Brazilian agribusiness. Custos E Agronegocio, v. 13 (Special edition), p. 203-226, 2017.

MARTINEZ, L. A theory of political cycles. Journal of Economic Theory, v. 144, n. 3, p. 1166-1186, 2009. doi: https://doi.org/10.1016/j.jet.2008.10.006

MARTINS, P.; CORREIA, L. Determinantes dos desvios orçamentais nos municípios portugueses. Revista Portuguesa de Estudos Regionais, v. 39, 2015. Retrieved from: http://www.redalyc.org/html/5143/514351601003/

NAKAGUMA, M. Y.; BENDER, S. Ciclos políticos e resultados eleitorais : um estudo sobre o comportamento do eleitor brasileiro. Revista Brasileira de Economia, v. 64, n. 1, p. 3-24, 2010. doi: http://dx.doi.org/10.1590/S0034-71402010000100001

NORDHAUS, W. D. The political business cycle. Review of Economic Studies, v. 42, n. 2, p. 169-190, 1975. doi: 10.2307/2296528

NUNES, G. S. Ciclos políticos orçamentários políticos orçamentários: uma análise das 
despesas em educação e saúde para os municípios do Rio Grande do Sul (2002-12). Indicadores Econômicos - FEE, v. 44, n. 4, p. 99-110, 2017. Disponível em $<$ https://revistas.fee.tche.br/index.php/indicadores/article/view/3898/3846>. Acesso em: 16/ago/2018.

PHILIPS, A. Q. Manipulating the masses: new theories of political cycles. Dissertation (Doctoral Program in Political Science) - Texas A\&M University, College Station, Texas, USA, 2017.

QUEIROZ, M. C. L.; SILVA, A. B. Ciclos políticos orçamentários no Estado do Ceará (19862006). Planejamento e Políticas Públicas, v. 35, p. 223-252, 2010. Disponível em <http://www.ipea.gov.br/ppp/index.php/PPP/article/view/202/196>. Acesso em: 17/set./2018.

QUEIROZ, D.B. Influência do ano eleitoral, da mudança de gestor público e do mandato eleitoral sobre mudanças na composição dos gastos públicos nos estados brasileiros. Anais... Congresso ANPCONT, 11, Belo Horizonte, Brasil, 2017.

ROBBINS, G.; TURLEY, G.; McNENA, S. Benchmarking the financial performance of local councils in Ireland. Administration, v. 64, n. 1, p. 1-27, 2016. doi: https://doi.org/10.1515/admin-2016-0009

RODRIGUES, M. A. V. Democracia vs. eficiência: como alcançar equilíbrio em tempo de crise financeira. Revista de Administração Pública, v. 51, n. 1, p. 88-104, 2017. doi: http://dx.doi.org/10.1590/0034-7612165400

SAKURAI, S. N. Testando a hipótese de ciclos eleitorais racionais nas eleições dos municípios paulistas. Estudos Econômicos, v. 35, n. 2, p. 297-315, 2005. doi: http://dx.doi.org/10.1590/S0101-41612005000200003

SAlVATO, M. A.; ANTUNES, P. C.; ARAUJO Jr, A.; SHIKIDA, C. Ciclos políticos: um estudo sobre a relação entre flutuações econômicas e calendário eleitoral no Brasil, 1985-2006. Revista de Economia e Administração, v. 7, n. 1, p. 1-20, 2007. doi: 10.11132/rea.2002.173

SHI, M.; SVENSSON, J. Political budget cycles: do they differ across countries and why? Journal of Public Economics, v. 90, n. 8-9, p. 1367-1389, 2006. doi: https://doi.org/10.1016/j.jpubeco.2005.09.009

SIDORKIN, O.; VOROBYEV, D. Political cycles and corruption in Russian regions. European Journal of Political Economy, v. 52, p. 55-74, 2018. doi: https://doi.org/10.1016/j.ejpoleco.2017.05.001 
SIQUEIRA, F. F. Ciclo político: uma revisão literária. In: Temas de Economia Aplicada Informações Fipe, 57-66, 2016.

TANTARDINI, M.; GUO, H.; GANAPATI, N. Social capital and public financial performance: lessons from florida. Public Performance \& Management Review, v. 40, n. 3, p. 480-503, 2017. doi: https://doi.org/10.1080/15309576.2016.1276463

TORRES, L.; PINA, V.; MARTÍ, C. Using non-mandatory performance measures in local governments. Baltic Journal of Management, v. 7, n. 4, p. 416-428, 2012. doi: https://doi.org/10.1108/17465261211272166

VEIGA, L.G.; VEIGA, F.J. Ciclos político-económicos nos municípios portugueses. Anais... II Conferência do Banco de Portugal. "Desenvolvimento Económico Português no Espaço Europeu", 2001. Retrieved from https://repositorium.sdum.uminho.pt/bitstream/1822/3822/1/BP_LFVeiga.pdf

VICENTE, E. F. R.; NASCIMENTO, L. A efetividade dos ciclos políticos nos municípios brasileiros: um enfoque contábil. Revista de Contabilidade e Organizações, v. 6, n. 14, p. 106-126, 2012. doi: http://dx.doi.org/10.11606/rco.v6i14.45402

ZUCOLOTTO, R.; TEIXEIRA, M. A. C. Transparência orçamentária: razões do descompasso entre os Estados brasileiros. Organizações \& Sociedade, v. 24, n. 82, p. 390-411, 2017. doi: $10.1590 / 1984-9240822$ 